\title{
Determination of groundwater availability in shallow arid region aquifers utilizing GIS technology: a case study in Hada AI-Sham, Western Saudi Arabia
}

\author{
A. S. El-Hames • K. A. Al-Ahmed
}

The online version of the original article can be found at http:// dx.doi.org/10.1007/s10040-004-0323-7

Hydrogeology Journal (2004)

DOI 10.1007/s10040-004-0323-7

The online version of the original article can be found at http:// dx.doi.org/10.1007/s10040-004-0323-7

As an appreciation for the contribution of $\mathrm{Mr} \mathrm{K}$. A. Al-Ahmed to this work, at a later stage, his name was added to this article as a co-author.

Published online: 31 July 2004

(C) Springer-Verlag 2004

A. S. El-Hames $(\bullet) \cdot$ K. A. Al-Ahmed

Department of Hydrology and Water Resources Management,

King Abdulaziz University,

P.O. Box 80208, Jeddah 21589, Saudi Arabia

e-mail: aelhames@kaau.edu.sa

Tel.: +966-2-6400000 ext. 64831

Fax: +966-2-6952376 